\title{
Major Causes of Organ Condemnation and Direct Financial Loss in Bovine Slaughter in Hawassa Municipal Abattoir Hawassa, Ethiopia
}

\author{
Zerihun Teshome and Hiwot Tesfaye
}

\begin{abstract}
This study was conducted from November 2009 to April 2010 on cattle slaughter at Hawassa municipal abattoir. An attempted was made to study major causes of organ condemnation and to estimate the direct finical loss due to the condemnation of edible organ. A total of 768 were examined by standard postmortem inspection procedure. Out of the $524(67.19 \%)$ livers $503(65.4 \%)$ lungs $59(7.7 \%)$ heart and $38(4.95 \%)$ kidney was rejected. The main causes of organ condemnation were fasciolosis, 295 (56.2\%) hydatidosis (61.8\%), nephritis $19(50 \%)$ and cystericuse bovis $27(45.7 \%)$, rendering them unfit for local market on aesthetic ground or zoonotic considering their risks to human being. The total annual financial loss due to condemnation of these organs was calculated to be 1,350,790 per annum. The result of this present work indicate immediate need the prevention of organ condemnation and pathological abnormality through development of animal health delivery enforcement of slaughter policy and training of slaughter house personnel on standard slaughter operation.
\end{abstract}

Keywords: abattoir, cattle, condemnation, organ, Hawassa

DOI: $10.7176 / \mathrm{JBAH} / 9-9-02$

Publication date:May $31^{\text {st }} 2019$

\section{INTRODUCTION}

Ethiopia has the largest livestock population in Africa, estimated at 49 million head of cattle 47 million small ruminant, 2.7 million horses, 5 million head of donkeys and about 76000 of camel 42 million chickens (CSA, 2009). However, this huge potential wealth is untapped to the live hold or village farmers and the contribution to national economy at large a minimal. This uneconomic explosion of livestock resource is due to prevailing disease, poor nutrition and absence of well developed market in restructure (MORD, 2005).

In Ethiopia live stock contributes about $30.35 \%$ of agricultural gross domestic product and more than $85 \%$ of farm cash income. They provide high quality food from consumption of fibrous and unusable resource. They serve as source of cash income and means of savings, import export commodity and provide raw materials for industries like leather industry. In Africa in general and in Ethiopia in particular, the level of ruminant livestock production doesn't commensurate with its size. (Berhanu, 2006).

Many animals and their by product are used for human consumption in Ethiopia. Red meat, milk, egg, honey and edible visceral organ are some in the list. One of the losses from endemic diseases is expressed in terms of organ condemnations. The most commonly affected organs are liver and lung the mainly due to Fasciolosis and hydatidosis (Teka, 1997).

Parasites in the tropics are responsible for greater losses to the meat industry than any other disease (Jober et.al., 1996). Similarly like many other tropical counties of Africa, it is well known that parasitic diseases are among the major factors responsible for the low productivity of live stock in Ethiopia (Abebe, 1995). These infestations not only cause clinical disease and mortality but also cause economic losses through production loses and condemnation of specific organs at slaughter. Various investigations have been conducted through abattoir surveys to determine the causes and asses the economic importance of organ contamination in Ethiopia. However most of the survey carried out indifferent abattoirs of the country paid much attention to the parasitic causes of organ condemnation namely of fasciolosis and hydatidosis as these are usually considered to have major economic and public health importance in meat inspection (Tilahun 1994, Jober, et al., 1996).

An abattoir or slaughter house as a building for butchering can be a source of valuable information of the incidence of animal disease and condition. Some of which may be zoonotic. It is food factory whose primary aim is to produce health, whole some and clean products which are safe for human consumption. In adequate care of these food animals reduce their productivities and expose them to different forms of disease agent which may become hazardous to mane and his environment (Cadmus, and Adesokan, 2009).

Meat is an important source of protein and valuable commodity in resource poor communities. In many developing countries lack of appropriate slaughtering facilities and unsatisfactory slaughtering techniques are causing unnecessary losses of meat as well as invaluable by-product from animal carcasses. Slaughtering place are frequently contaminated and may not be protected against dogs, rodents and insect meat products coming from such condition are often deteriorated due to bacterial infection or contaminated which may cause food poisoning or diseases in consumer. In many developing countries regulations concerning meat inspection and/or control are inadequate or non-existent allowing consumer to be exposed to pathogens including zoonotic parasite 
(Alemu and Merkel, 2008).

Meat inspection is commonly perceived as the sanitary control of slaughter animal and meat. The aim of meat inspection is to provide safe and wholesome meat for human consumption. Routine postmortem examination of carcass should be carried out as soon as possible after the completion of dressing in order to detect any abnormalities so that products only conditionally fit for human consumption are passed for food. All organs and carcass portions should be kept together and correlated for inspection before they are removed from the slaughter floor (FAO 1994).

Activities of the meat sector may be divided in to three stage, slaughtering, meat cutting and processing. Improper slaughtering technique such as faulty stung, evisceration and carcass splitting can damage parts at the carcasses and certain by product and make them unusable for further use. Poor standards of hygiene during slaughtering or carcass handling result in high level of microbial contamination in the product. All these are responsible for carcass and organ condemnations. As meat is the main source of protein for man it should be clean and free from diseases of particular importance to the public such as tuberculosis hydatidosis cysticercosis and fasciolosis (Sirak, 1991).

The main causes of organ condemnation during postmortem inspection are disease originated by parasite, bacteria and virus; of these diseases liver fluke in the liver and hydatid cyst in the liver, lung and kidney are mainly involved (Teka, 1997).

The final judgment as to the action to be taken with an organ or carcass or parts of the carcass is based on the total evidence produced by observation, palpation incision, smell any ante-mortem sign and result of any laboratory tests. It is necessary to be aware of the extent to which the public is exposed to certain zoonotic diseases detected in the abattoir and the financial losses resulting from condemnations of affected organs (Teka 1997).

Diseases that occur in livestock have two major impacts on the society. These are economic and public health impacts. These two major impacts have highly pronounced effect on the large scale abattoirs where there are large numbers of animal slaughtered and large number of workers present. In addition to the risk on them, abattoirs have high responsibility to provide risk free products to the society (Hanna, 2007). Abattoir provide information on the epidemiology of disease on livestock, to know to what extent the public is exposed to certain zonotic disease and estimate the financial losses incurred through condemnation of affected organs and carcasses (Nif and Along 1987, Vanlongtestisin, 1993).

Each year a significant financial loss results from weight gain, condemnation of edible organs and carcasses at slaughter. This production loss in livestock industry if estimated at more than 900 million USD annually (Abebe, 1995; Jobre et al., 1996). It is necessary to be aware of the extent to which the public is exposed to certain zoonotic diseases detected in the abattoir and estimate the financial losses through condemnation of affected organs and carcass (Nif and Along, 1987).

Various investigations have been conducted through abattoir survey to determine the economic importance of organ and carcass contamination in Ethiopia (Jembere, 2002, Yimam, 2003, Ezana, 2008, Jibat et al., 2006).

Disease causes extensive financial wastes as a result of direct and indirect economic losses. Study conducted indifferent abattoir of Ethiopia revealed that parasitic infection of liver, pneumonia and nephritis are found to be the major cause of organs condemnations (Jibat et al., 2006; Yimam, 2003).

The objectives of this study were

- To identify the significant causes of organs and carcass condemnation of cattle slaughtered at Hawassa Municipal Abattoir

- To estimate the magnitude of direct financial loss attributed to the condemned organ and carcasses.

\section{MATERIALS AND METHODS}

\subsection{Study Area}

The study was conducted from November 2009 up to April 2010 in Hawassa town Southern Nation Nationalities and People Region. Hawassa is the capital city of Sidama Zone and the region. It is Located on the shore of one of the rift valley lakes and found at $275 \mathrm{~km}$ south of Addis Ababa. The total population of Hawassa is estimated to be 150.000 , dwelling over an area of $50 \mathrm{~km}^{2}$. The annual rainfall and temperature range of the town is 800 $1000 \mathrm{~mm}$ and $20.1-25^{\circ} \mathrm{c}$ respectively. The total livestock population of Sidama zone including Hawassa is estimated to constitute 1,721,341 Cattle, 228,941 Goats, 457,465 Sheep, 57,643 Horses, 54,066 donkeys, 725,540 Poultry and 44,492 beehives. Livestock production occupies an enormous share in farm economy of the area. They are kept for milk production where as equine are used in pulls carts, carrying people and goods in the town nearby villages adding to income generation employment opportunity in the town. Considerable number of small ruminants is also kept in Hawassa as income generation for poor residents. As elsewhere in rural Ethiopia the economic life of the people in the surrounding of Hawassa is mostly dependent on mixed farming in the $93 \%$ of population is engaged in agriculture (SZARDB, 2008). 


\subsection{Study Animal}

The cattle destined for slaughter were mostly male originated from different parts of the neighbored country including Walyita, Bishan guracha, Harar, Arsi Nagale, Adama, and also from the city i.e. Hawassa. A total of 768 cattle destined for slaughter were inspected during post mortem inspection with their specific identification numbers and recorded accordingly on a format prepared for this purpose

\subsection{Study Design}

A cross- sectional study was conducted in cattle slaughtered in the Hawassa municipal abattoirs. The study subjected was selected using the systemic random sampling method. Three working dates were selected out of a week for conducting the postmortem examination. The study animal was identified by number that was assigned in personnel in the abattoir and was written on the skin of the animal prior to slaughter in the lairage.

\subsubsection{Post Mortem Examination}

During postmortem inspection liver lungs heart kidneys and carcasses were thoroughly inspected by visualization, palpation and making systemic incision where necessary for the presence of cysts, parasite and other abnormalities Pathological lesion were differentiated and judged according to guidelines on meat inspection for developing countries and the result were recorded and the decision at postmortem inspection are classified in to the following categories of judgment such as approved as fit for human consumption conditionally approved as fit for human consumption, totally condemned as unfit for human consumption and partially condemned as fit for human consumption (FAO, 1994).

\subsection{Finical Loss Assessment}

In assessing the finical loss due to condemnation of liver, lung, heart and kidney from market were considered. The analysis was based on annual slaughter capacity of the abattoir considering market demand, average local market priced of the organ in Hawassa city and rejection rate of liver, lung, kidney, and heart. The annual slaughter rates were estimated from retrospective abattoir record of the past two years. Average market prices of liver lung, and kidney were determined from interviewee made with personnel of the abattoir and local butcher house. The Financial losses due to organ condemnation were estimated by the formula set by as follow Ogunirade and Oguninda. (1980).

$\mathrm{EL}=\sum \operatorname{srx} \mathrm{X} \operatorname{Coy} \mathrm{X} \operatorname{Coy} \mathrm{X}$ Roz

$\mathrm{EL}=$ Annual economic loss estimated due to organ condemnation from local markets.

$\sum$ srx $=$ Annual cattle slaughter rate of the abattoir

Coy $=$ Average cost of each bovine liver/lung/heart/kidney

Roz $=$ Rejection rate (condemnation) rates of bovine liver/ lung//heart/kidney

\subsection{Data Management and statistical Analysis}

Data generated from post mortem meat inspection were recorded in Microsoft excel 2007 program. Analysis was done by SPSS; software version 13.0. Descriptive analysis like frequency, percentage was used to determine the level of organs condemnation rate which was defined as proportion of organ examines. The association between condemnation rate of organs of animal was assessed by Pearson chi-square $\left(\mathrm{x}^{2}\right)$ and difference were regarded statistically significant at $\mathrm{p}$ value less than 0.05

\section{RESULT}

\subsection{Postmortem inspection}

Out of 768 cattle slaughter in the abattoir by standard post mortem examination, $524(67.78 \%)$, liver 503 (65.49\%) lung 59 (7.68\%) heart and $38(4.9 \%)$ kidney was condemned due to the various reasons.

\section{Liver condemnation}

The overall liver condemnation rate due to various pathological findings was $67.8 \%(521 / 768)$. The causes of liver condemnation encountered during the study were summarized in (Table 1) fasciolosis, hydatidosis, calcification, fasciolosis and hydatidosis and abscessation were responsible for the rejection of $56.2 \%, 25.5 \%$, $15.4 \%, 2.3 \%, 0.57 \%$ respectively. Fasciolosis was determined to be the major causes of liver rejection followed by hydatidosis. 
Table 1. Summary of liver condemnation and its rejection rate in Hawassa municipal abattoir

\begin{tabular}{llll}
\hline Causal factors & $\begin{array}{l}\text { Number } \\
\text { condemned }\end{array}$ & $\begin{array}{l}\text { Rejection } \\
\text { rate }\end{array}$ & 95\%CI \\
\hline Fasciolosis & 295 & 56.2 & $52.0-360.7$ \\
Hydatidosis & 133 & 25.5 & $21.7-29.39$ \\
Calcification & 81 & 15.4 & $12.4-18.84$ \\
Fasciolosis and hydatidosis & 12 & 2.3 & $0.8-2.7$ \\
Abscessation & 3 & 0.57 & $0.1-1.6$ \\
\hline Total & 524 & $100 \%$ & \\
\hline
\end{tabular}

\section{Lung condemnation}

From the total number of cattle slaughtered, $503(65.5 \%)$ had total lung condemned for gross abnormality. Hydatidosis was responsible for the rejection rate $61.8 \%$ lungs being a principal cause, other condemnation that were found during the study were emphysema, pneumonia, and hydatidosis and emphysema, of $17.45 \%, 12.9 \%$, $7.75 \%$ respectively.

Table 2. Summary of lung condemnation and its rejection rate in Hawassa municipal abattoir.

$\begin{array}{lll}\text { Pathological lesion } & \text { Number condemned } & \text { Rejection }\end{array}$

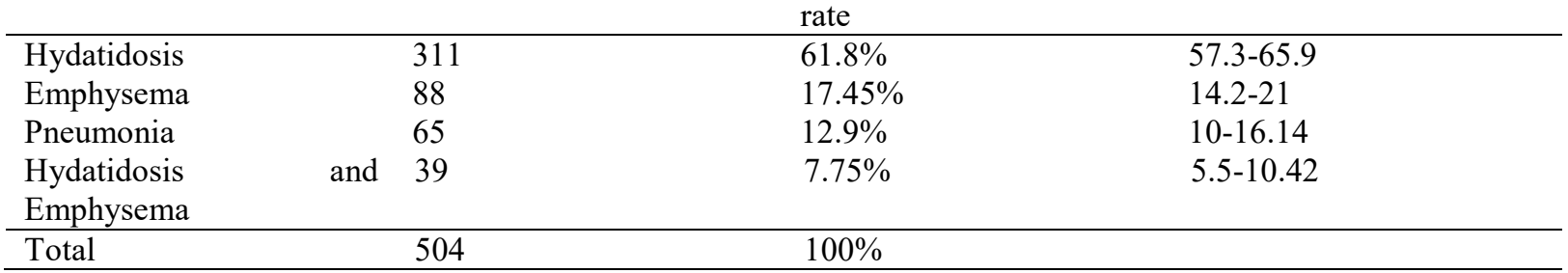

\section{Kidney condemnation}

A total of 38 kidneys were condemned during the study period. Nephritis, hydatidosis, calculi and infract (Table 3 ) were the abnormalities determined with a respective rejection rate of $50 \% 36.84 \%, 7.84 \%$ and $5.25 \%$ and nephritis was found to be the principle cause for the rejection rate.

Table 3. Summary on kidney condemnation and its rejection rate

\begin{tabular}{llll}
\hline Pathological lesion & Organ condemned & Rejection rate & $95 \% \mathrm{CI}$ \\
\hline Nephritis & & & $33.3-66.6$ \\
Hydatidosis & 19 & 50 & $21.8-54.00$ \\
Calculi & 14 & 36.84 & $1.6-21.3$ \\
Infract & 3 & 7.84 & $0.6-17.4$ \\
\hline Total & 2 & 5.25 & \\
\hline
\end{tabular}

\section{Heart condemnation}

Out of the total 59 heart with gross abnormalities cysticercus bovis, hydatidosis, pericardities caused $45.7 \%$, $37.28 \%, 16.95 \%$ rejection rate respectively. Cysticercus bovis was found to be the principally causes for the rejection rate of heart. (Table 4)

Table 4. Summary of heart condemnation and its rejection rate

\begin{tabular}{llll}
\hline Pathological lesion & frequency & Rejection Rate & $95 \%$ CI \\
\hline Cysticercus bovis & & & \\
Hydatidosis & 27 & $45.7 \%$ & $32.7-59.2$ \\
Pericarditis & 22 & $37.3 \%$ & $25.04-50.8$ \\
\hline Total & 10 & $16.9 \%$ & $8.4-28.96$ \\
\hline
\end{tabular}

\subsection{Annual finical loss assessment}

Annual economic loss was estimated from the summation of total rejected organs (liver, lung, heart, and kidney) of cattle slaughtered at Hawassa municipal abattoir. The annual rate of organ condemnation was assessed considering the overall rejection rate of each organ, the total annually slaughtered animal and retailed market price of an average size cattle organ. Annual slaughtered rate of cattle was estimated to be 32,000 . While the retail market was determined from the interview made with the butchers in Hawassa. Information obtained was then subjected to mathematical computation using the formula set by Ogunirade and Ogunrinde (1980). This was found to be about 1,350,790 ETB (Table 5) 
Table 5. The average estimated economic losses incurred annually due to condemned organs

\begin{tabular}{llccl}
\hline Organ & Average rejection & $\begin{array}{c}\text { Average annual } \\
\text { slaughter rate of } \\
\text { cattle }\end{array}$ & $\begin{array}{c}\text { Annual market } \\
\text { price of organ }\end{array}$ & Total \\
\hline Liver & $67.19 \%$ & 30,000 & $50.00 \mathrm{ETB}$ & $1,091,666 . \mathrm{ETB}$ \\
Lung & $65.49 \%$ & & $10.00 \mathrm{ETB}$ & $209,583 \mathrm{ETB}$ \\
Heart & $7.68 \%$ & & $15.00 \mathrm{ETB}$ & $36,875 \mathrm{ETB}$ \\
kidney & $4.9 \%$ & & $8.00 \mathrm{ETB}$ & $12,666 . \mathrm{ETB}$ \\
\hline Total & & & & $1,350,790 \mathrm{ETB}$ \\
\hline
\end{tabular}

\section{DISCUSSION}

In Ethiopia many studies have been undertaken to identify the major disease condition encountered during antmortem and postmortem examination. The study conducted by Shiferaw (2002), Mezigabu (2003) and Kifely (2008) at Nazeret, Gondar and Dire Dawa abattoir revealed that liver and lung was highly rejected organ by post mortem inspection and fasciolosis and hydatidosis were the major causes of rejection rate.

In this study 3840 organs obtained from 768 animals 521 livers, 503 lungs, 59 hearts and 38 kidneys were rejected from the total market. There is no export of organ since the abattoir is not standardized. The rejected organs which were found unfit for human consumption and as pet animal feed were incinerated in the abattoir to break the life cycle of disease transmission.

In current study $521(67.8 \%)$ liver were rejected rate out of 768 cattle examined at postmortem. The most frequent observed pathological condition were fasciolosis, hydatidosis, calcification, Fasciolosis and hydatidosis and ,abscessation (Table 2) of which fasciolosis occupies the highest rate i.e. 56.6\% causing considerable direct finical losses in the study area. This result agree with the findings of Teka (1997), Andualem (2007) and Shegaw (2008) who stated that liver flukes in the liver and hydatid cyst in the lung among the main causes of organ condemnation during postmortem inspection. Besides out of 768 lungs examined 501 lungs were rejected. The causes of rejection were hydatidosis, emphysema and abscessation, hydatidosis was found to be the principal causes of lung condemnation which was responsible for the rejection rate of $311(61.82 \%)$.

In Ethiopia fasciolosis has been reported to be one of the major diseases problem of livestock industry Daniel (1995), Shegaw (2008), Gemachu (2008) and Birehanu (2006) reported a rejection rate of 14.4\%, 43.7\%, $53.9 \%$, 50\% liver due to Fasciolosis at Dire Dawa, Gondar, Haramaya and Addis Ababa abattoirs respectively.

The current study revealed that the prevalence rate of Fasciolosis which was recorded to be $56.2 \%$ is slightly higher when compared with privies study done at the same study area with a prevalence rate $54.8 \%$ Fitsum; (2009); but this lower than previous report from different part of country Tilahun 71\% (1994), Jemal $68.7 \%$ (2009), Nigatu $71 \%$ (2009)

The relative low prevalence of bovine fasciolosis observed in this study as compared to the findings of other studies may be attributed to the agro ecological condition unsuitable for the development of snail intermediate host prevailing in the areas from which the slaughtered animals were brought. In Ethiopia bovine Fasciolosis exist almost in all region (Bahiru and Ephrem, 1979)

Hydatidosis is zoonotic disease that occurs throughout the world and cause considerable economic loses and public health problem in many countries (Budke et al., 2006). It also the main disease in ruminat and man in Ethiopia affecting primary the lung and liver (Fisseha and Yilma, 1997; Teka1997). Have been indicated that significant economic losses are incurred due to bovine hydatidosis from liver, lung, kidney, heart, and carcass weight loses.

In countries like Ethiopia the wide spread of back yard animal slaughter practice, corresponding absences of standard meat inspection procedure and feeding of dogs with condemned organs facilitates land maintain the perfect life cycle of the parasite in the ruminates. These conditions are very common in the rural areas

During this study lungs were condemned as a result of the major pathological lesion detected. The lesion found were hydatidosis which stood first with a prevalence of $61.8 \%$ followed by $17.5 \%, 12.9 \%, 7.75 \%$ emphysema, pneumonia and hydatidosis and emphysema respectively were the major causes of lung condemnation

The current study revealed that the prevalence rate of hydatidosis is which was recorded to be $61.8 \%$ which is almost similar compared with previous report made at the same study area with a prevalence $64.56 \%$ Fistum, (2009), also higher than Andualem (2007), Shegaw (2008), 25.2\%, 24.3\%, respectively. Even a lower prevalence of bovine hydatidosis $4.8 \%$ and 5.6\% were reported in Kenya (Cerlinat, 1983) and in Libya (Mohammed, 1985) respectively.

Factors governing prevalence of hydatidosis in a given locality may be associated with prevailing specific social, cultural, environmental and epidemiological situation (Macpherson, 1985). In agreement with present study many research reported that liver and lung were the most commonly affected organs by hydatid cyst (Jobber et al., 1996; Urquhart et al., 1997) Particularly the lungs is the organ most affected by hydatidosis 
because at old age the liver capillaries are dilated and most cyst passed directly to the lung, secondly the cyst passes to the lung via the thoracic duct without involving the liver (Gracey, 1986). The reason as explained by (Gracey 1986) is that lung and liver contain the highest capillary bed in the body. The majority of oncoseper are filtered out and trapped in the fine blood capillaries and only small number of oncoseper reached the reaming organs.

The rejection rate of kidney and heart was not as significance as those of liver and lung and such unlike to produce the pronounced economic effect associated with the first two. During the study period bovine kidney were rejected mainly due to nephritis, hydatidosis, calculi, infracts. However, nephrites accounts for the most and major causes for the kidney to be condemned, with comprise about $50 \%$ of all rejected kidney this result agree with Nishanwork (2009), Jemal (2009), and Kifley (2008) was stated that nephritis was major causes of kidney condemnation. This is because of higher incidence of focal interstitial nephritis in older cattle (Monaghane and Hannan, 1983).

Many workers in Ethiopia have indicated on animal basis the higher economic losses was condemnation of edible organ and carcass due to parasitic infestation (Kifley, 2009 Ezana 2008, Andualem, 2007). A total loss was of, 1, 350, 790, ETB in cattle was incurred in the abattoir only duet to condemnation of edible organs this amount didn't include the losses from poor flaying techniques that down grade the quality of hided and other consideration generally such rejection undoubtedly are casting to mach losses to the livestock industry. Among the total losses $80.8 \%$ was due to condemnation of liver. The present study suggested that parasites particularly fasciolosis and hydatidosis were the major causes of economic loss through condemnation of affected organ. Annual losses in animal productivity due to fasciolosis were conservatively estimated to approximately 3.2 billion per annum (Spithill et al., 1999). The result of this work clearly demonstrate the need to develop effective control measures on the prevention and control of cattle parasite so as to decrease the direct and indirect economical loses that can occur in the livestock production system of the country.

\section{CONCLUSION AND RECOMMENDATIONS}

Livestock and livestock product provide vital source of food and major export resource in countries like Ethiopia which has large number of animal. According to the result of this study hydatidosis Fasciolosis nephritis and cystcercius bovis are the most common and major causes of rejection cattle organs in the study area and results 1,350,790 financial losses per annum. In addition, the findings of hydatidosis at such high rate indicate the presence of echinicocosis in higher prevalence in the final host in the area. Therefore, the public health significance is immense.

Based on the findings of the. Studies the following recommendation are forwarded

The epidemiology of these diseases causing organ condemnation has to be studied in detail

- Standard meat inspection procedure should be properly conducted in municipals and export abattoir to provide safe and whole some meat to the consumer

- Doges should be prevented from eating raw offal and must be dewormed frequently and offal should be properly disposed.

- Abattoir workers and consumer must give attention during handling of carcass and consumption of raw or under cooked beef.

- Governments should have prohibited backyard slaughtering in different localities and encourage investors who have capacity to build modern abattoir in different area of the contrary.

\section{REFERENCES}

Abebe, G. (1995). Current status of veterinary education and health research in Ethiopia In veterinary medicine impact on human health and nutrition in Africa proceeding of an international conference. International livestock Research institute (ILRI) Addis Ababa, Ethiopia. Pp 133-138

Alemu, Y. U and Merkel, C. (2008). Sheep and goat production hand book for Ethiopia. Ethiopia sheep and goat productivity improvement program

Andualem, Y. (2007). Causes of organ and carcass condemnation of cattle slaughtered in Kombolcha Elfora Meat Factory DVM Thesis, Addis Ababa University, Faculty of Veterinary Medicine, Debre Zeit, Ethiopia

Bahiru, G. G. and Ephraim, M. (1979). A Preliminary survey of bovine facsiolosis in Ethiopia. Journal of Agriculture Science 1.5-12

Berhanu, M. (2006). Major causes of organ condemnation cattle and sheep slaughter in Addis Ababa Abattoirs Enterprise. DVM Thesis, Faculty of Veterinary Medicine, Addis Ababa University, Debre Zeit, Ethiopia.

Budke, B, C., Depletes, P. and Torgerson, P .R. (2006). Global socio economic Impact of Cystic echinoccocis. Emerging Infectious Diseases. 12,296-303

Cadmus, S. I. B. and Adesokan, H. K (2009). Causes and implications of bovine organs/Offal condemnations in some abattoirs in western Nigeria. Department of veterinary public Health \& preventive medicine, Faculty of Veterinary Medicine University of Ibadan. Ibadan Nigeria. Pp 1-2 
Central Statistical Agency (2009): Federal Republic of Ethiopia central statistical agency, agricultural sample survey 2008/2009 (2001 E.C.): Report on livestock and livestock characteristics, statistical bulletin Pp 446: 39

Cerlinat, H. K. (1983). Bovine helminthes parasite of economic importance. Bulletin Animal Health Production Africa 13:368-375

Daniel, F. (1995). Economic importance of organ condemnation due to Fasciolosis and hydatidosis in cattle and sheep slaughter at Dire Dawa abattoir. DVM Thesis Faculty of Veterinary Medicine Addis Ababa University Debre Zite Ethiopia. Pp 20-22

Ezana, G. (2008). Major Diseases of Export oriented livestock in Export Abattoirs in and around Aada'a liben woreda. DVM Thesis Faculty of Veterinary medicine Haramaya University, Haramaya Ethiopia.

FAO, (1994). Food and Agriculture Organization of the United Nation Manual and health production paper.

Fisseha, G. and Yilma, J. (1983). Economic importance of bovine fasciolosis an assessment trial at Debra Zite abattoir. DVM Thesis, Faculty of Veterinary Medicine Addis Ababa University Debre Zite Ethiopia. Pp 2022

Fistum, A. (2009). Major causes of lung and liver condemnation and its economic importance in Hawassa municipal abattoir DVM Thesis, Gondar University, Faculty of Veterinary Medicine, Gondar Ethiopia

Gemechu G (2008). Prevalence of bovine Fasciolosis in and round Haramaya town DVM Thesis Faculty of Veterinary medicine Haramaya University, Haramaya Ethiopia.

Gracey, J, F. (1986). Meat hygiene $8^{\text {th }}$ ed London Baliire Tindane

Hanna, Z. (2007). Prevalence and economic significance of cystic hydatidosis in small Ruminant slaughtered at Debre Zeit HELMEX abattoir DVM thesis Mekelle University, Faculty of Veterinary medicine. Mekelle, Ethiopia.

Jemal, T. (2009). Major causes of organs condemnation in cattle slaughtered at Kombolcha Elfora Meat Factory Abattoir South Wello, Ethiopia. DVM Thesis Faculty of veterinary Medicine, Haramaya University. Haramaya, Ethiopia

Jembere, S. (2002). A survey of causes of organ condemnation in slaughtered cattle at Nazareth Abattoir, DVM Thesis faculty of Veterinary Medicine. Addis Ababa University Debre Zeit, Ethiopia. Pp 23

Jibat. T., G. Ejeta, Y., Asfaw and Nusie.A. (2006). Causes of abattoir condemnation in apparently health slaughtered sheep and goats in HELMEX abattoir Debre Zeit, Ethiopia. Pp 31

Jobre, V, Lobago, F., Tirunesh, R., Abebe, G. and Dorchies, P. (1996). Hydatidosis in three selected regions in Ethiopia. An assessment trial on its prevalence, economic and public health importance. Revolution. Medicine. Veterinary 1:797-804

Kiflay, G. (2008). A study on the major causes of organ condemnation and their economic importance in bovine Mekelle Municipal Abattoir. DVM Thesis, Addis Ababa University, Faculty of Veterinary Medicine, Debre Zeit, Ethiopia

Macpherson, M, C .L (1985). Epidemiology of hydatidosis cyst in Kenya. A study of the domestic characteristic hosts in Masula. The royal society of tropical medicine and hygiene. Pp 203-217.

Mezigebu Y, (2003). Major causes of organ condemnation in ruminant slaughtered at Gondar abattoir, DVM Thesis, Addis Ababa University, Faculty of Veterinary Medicine, Debre Zeit, Ethiopia

Ministry of agriculture and rural development (2005). Agricultural rural development. Bulletin (Amharic version $2^{\text {nd }}$ year No 40)

Mohammed, A. (1985). Prevalence of Echinoccocus granulosus among domestic animals in Libya. Tropical Animal, Health Production. 11: 169.70

Mongan, M. L and Hannan J. (1983) Abattoir survey of bovine kidney disease veterinary record 113:55-57

Nif, A. N and Alonge, D. O, (1987). An economic survey of abattoir data in Fako divison ofsouth west Province Cameron. Bulletin of Animal Health Production 23: 155-167

Nigatu, K. (2009). A retrospective survey of bovine hydatidosis in three abattoir of Amhara National Regional state North West Ethiopia. Tropical Animal Health prods 2:42-45

Nishanwork, W. (2009). Major causes of organ condemnation and economic loss in Bovine Slaughtered in Addis Ababa Abattoir Enterprise. DVM Thesis faculty of Veterinary Medicine Haramaya University. Haramaya, Ethiopia

Orgunriade, A.F and Ogunrinade, B .I. (1980). Economic important of bovine Fasciolosis in Nigeria. Tropical .Animal .Health Pro.12:155.15

Shegaw, S. (2008).The study on causes of organ condemnation in slaughtered cattle at Mekelle abattoir DVM Thesis, Addis Ababa University, Faculty of Veterinary Medicine, and Debre Zeit, Ethiopia

Shiferaw, J. (2002). The study on causes of organ condemnation in slaughtered cattle at Nazareth abattoir. DVM Thesis, Addis Ababa University, Faculty of Veterinary Medicine, Debra Zeit, Ethiopia

Sirak, A. (1991). Causes of organ condemnation in Bahir Dar abattoir proceedings of the $4^{\text {th }}$ national live stock improvement conference. Institute of Agricultural Research Addis Ababa Ethiopia. 
Spithil, T.W, Smoker, P. M., Copeman, D.P (1999). Fasciola gigantica epidemiology, control immunology and molecular biology.IN Dalton. pp 465-525

SZARDB, (2008). Sidama zone agriculture rural development biro.

Teka, G. (1997). Meat hygiene In: Food hygiene principles and methods of food borne disease control with special reference to Ethiopia. Pp 95-113

Tilahun, G. (1994). Animal disease of gastro intestinal tract and Liver. An Africa prospective proceeding of seminar IFS. Pp 133-138

Urquhart , G.M., Armoure , J., Duncan, J, L., Dunn., A.M and Jennings, F.W (1997) . Veterinary Parasitology .Scotland Black well science

Vanlongtestisin, J. G. (1993). Integrated quality meat safety. A new approach Meat focuses International 2. Pp 123-12

Yimam, M. (2003). Major causes of organ condemnation and economic importance assessment on cattle slaughtered at Bahir Dar municipal abattoir. DVM Thesis Faculty of Veterinary Medicine Addis Ababa University Debre Zeit 